\title{
Dimensões dos direitos fundamentais no Plano Nacional de Políticas para Mulheres ${ }^{1}$
}

\author{
Dimensions of fundamental rights in the National Plan of Policies for Women
}

Dimensiones de los derechos fundamentales en el Plan Nacional de Políticas para la Mujer

Maria Eliane Alves Sousa ${ }^{2}$

Maria de Fátima Lobato Tavares ${ }^{3}$

Rosa Maria da Rocha ${ }^{4}$

\begin{abstract}
Resumo
Objetivo: analisar as propostas de ações das três versões do Plano Nacional de Políticas para Mulheres (PNPM) como contribuições ao desenvolvimento dos direitos humanos das mulheres no Brasil, especialmente o direito à saúde. Metodologia: pesquisa teórica e documental sobre o avanço histórico dos direitos das mulheres como dimensões de direitos, em aspectos relacionados à atenção do Estado em políticas públicas de promoção da saúde. A revisão documental foi adotada como procedimento técnico de observação indireta por meio de documentos oficiais, tendo como fontes dos dados secundários os textos das três versões do Plano Nacional de Políticas para Mulheres, disponíveis em sítios oficias do governo brasileiro. Resultados: os PNPM trazem a narrativa da busca de inovações e avanços nos direitos das mulheres, porém as ações propostas concentram-se mais nas práticas tradicionais para a saúde reprodutiva. Conclusões: apesar de algumas limitações, as estratégias e ações dos planos podem contribuir para desenvolver aspectos de cidadania e direitos que visam incrementar a vivência social e a equidade, diminuir as vulnerabilidades e melhorar a qualidade de vida.
\end{abstract}

Palavras-chave: Direitos humanos. Direito à saúde. Direitos da Mulher. Políticas públicas. Justiça social.

\footnotetext{
Abstract

Objective: to analyze the proposals of actions of the three versions of the National Plan of Policies for Women (PNPM, in Portuguese) as contributions to the development of the human rights of women in Brazil, especially the right to health. Methodology: theoretical and documentary research on the historical advancement of women's rights as dimensions of rights, in aspects related to the attention of the State in public health promotion policies. The

${ }^{1} \mathrm{O}$ presente artigo é parte dos resultados de pesquisa da dissertação de mestrado intitulada Promoção da saúde e equidade: contribuições dos Planos Nacionais de Políticas para Mulheres em situação de vulnerabilidade, desenvolvida no Programa de Pós-graduação em Saúde Pública da Escola Nacional de Saúde Pública da Fundação Oswaldo Cruz, em 2018.

${ }_{2}$ Mestre em Saúde Pública pela Fundação Oswaldo Cruz (Rio de Janeiro). Advogada. Docente da Universidade Estadual da Bahia. E-mail: measud@gmail.com

${ }^{3}$ Doutora em Saúde Pública. Pesquisadora e docente do Departamento de Administração e Planejamento em Saúde, Escola Nacional de Saúde Pública, Fundação Oswaldo Cruz (Rio de Janeiro). E-mail: flobato@ensp.fiocruz.br

${ }^{4}$ Doutora em Saúde Pública. Pesquisadora e docente do Departamento de Administração e Planejamento em Saúde, Escola Nacional de Saúde Pública, Fundação Oswaldo Cruz (Rio de Janeiro). E-mail: rosaensp@gmail
} 
documentary revision was adopted as a technical procedure of indirect observation through official documents, using as sources of secondary data the texts of the three versions of the National Plan of Policies for Women, available in official sites of the Brazilian government. Results: PNPM brings the narrative of the search for innovations and advances in women's rights, but the proposed actions focus more on traditional practices for reproductive health. Conclusions: Despite some limitations, the strategies and actions of the plans can contribute to develop aspects of citizenship and rights that aim to increase social experience and equity, reduce vulnerabilities and improve the quality of life.

Keywords: Human rights. Right to health. Women's rights. Public policy. Social justice.

\section{Resumen}

Objetivo: analizar las propuestas de acciones de las tres versiones del Plan Nacional de Políticas para las Mujeres (PNPM) como contribuciones al desarrollo de los derechos humanos de las mujeres en Brasil, especialmente el derecho a la salud. Metodología: investigación teórica y documental sobre el avance histórico de los derechos de las mujeres como dimensiones de los derechos, en aspectos relacionados con la atención del Estado en las políticas de promoción de la salud pública. La revisión documental se adoptó como un procedimiento técnico de observación indirecta a través de documentos oficiales, utilizando como fuentes de datos secundarios los textos de las tres versiones del Plan Nacional de Políticas para la Mujer, disponibles en los sitios oficiales del gobierno brasileño. Resultados: PNPM trae la descripción de la búsqueda de innovaciones y avances en los derechos de las mujeres, pero las acciones propuestas se centran más en las prácticas tradicionales de salud reproductiva. Conclusiones: A pesar de algunas limitaciones, las estrategias y acciones de los planes pueden contribuir a desarrollar aspectos de ciudadanía y derechos que tienen como objetivo aumentar la experiencia social y la equidad, reducir las vulnerabilidades y mejorar la calidad de vida.

Palabras Ilave: Derechos humanos. Derecho a la salud. Derechos de la Mujer. Políticas públicas. Justicia social.

\section{Introdução}

A Organização das Nações Unidas (ONU) elaborou institutos específicos para as mulheres em relação ao desenvolvimento humano como direito: inicialmente, em 1949, criou a Comissão sobre o Status da Mulher; em 1975, estabeleceu aquele ano como o Ano Internacional da Mulher e a Década ONU para a Mulher para o período de 1976 a1985; em 1979, a Convenção sobre a Eliminação de Todas as Formas de Discriminação contra as Mulheres (CEDAW, em inglês) (1); em 1993, a Declaração e Programa de Ação da Convenção de Viena, que versa sobre os direitos humanos das mulheres e meninas (2); e, em 1994, a Convenção Interamericana para Prevenir Punir e Erradicar a Violência Contra a Mulher $(3,4)$.

Com base no relatório de desenvolvimento humano chamado La revolución hacia la igualdad en la condición de los sexos, de 1995 (5), a ONU inseriu na agenda pública mundial 
um conjunto de ações em prol das mulheres, de modo a envolver lideranças políticas, governantes, intelectuais, técnicos e organizações da sociedade civil, e sugeriu que os governos, em suas agendas públicas locais, tomassem providências para acabar com desigualdades de gênero, explorações e violências, e dar atenção especial à saúde das mulheres.

Também em 1995, realizou na China a IV Conferência sobre a Mulher, consagrada na Plataforma de Ação de Pequim (Ação para a Igualdade, o Desenvolvimento e a Paz), que estabelece importantes inovações sobre a igualdade de gênero, o empoderamento e a transversalidade para que as mulheres tenham condições de exercer seus direitos como direitos humanos das mulheres e meninas, de modo a atingirem seu desenvolvimento integral como pessoas (6).

Como país signatário da ONU, o Brasil assinou todas as convenções sobre a mulher, em busca de reconhecer a necessidade de adotar medidas de atenção especial à situação das mulheres, principalmente nas questões sobre a saúde. Em 1984, elaborou o Programa de Assistência Integral à Saúde da Mulher (PAISM), posteriormente transformado na Política Nacional de Atenção Integral à Saúde da Mulher (PNAISM) (7). Em 1985, criou o Conselho Nacional dos Direitos da Mulher e, em 2003, a Secretaria de Políticas para Mulheres (SPM) da Presidência da República (8). A SPM elaborou as três versões (2004-2007(8); 20072011(9); 2013-2015 (10)) do Plano Nacional de Políticas para Mulheres (PNPM), para promover a melhoria das condições de vida e saúde.

Os PNPM são concebidos como importantes conquistas e melhorias dos direitos das mulheres, sob a forma de políticas de combate às desigualdades de gênero, e de promoção de seu desenvolvimento humano. Compreendem as mulheres como um grupo composto por diversidades étnicas, sociais, econômicas, orientação sexual, faixa etária, e em condições de necessidades e degradações diferentes em tais diversidades. Por isso, anunciam propostas para a melhoria das condições de vida e saúde das mulheres em suas realidades cheias de múltiplas necessidades: saúde, moradia, trabalho, educação, segurança etc. Propõem políticas públicas articuladas com conhecimentos e âmbitos que estão além dos setores da saúde, mediante estratégias e ações específicas para os seguintes eixos: mundo do trabalho e autonomia econômica; educação; saúde integral, direitos sexuais e direitos reprodutivos; enfrentamento de violências, discriminações e desigualdades; participação nos 
espaços de poder; desenvolvimento sustentável; cultura, esporte, comunicação e mídia (810).

Sob tais aspectos, os PNPM propõem medidas que articulam políticas públicas saudáveis, intersetoriais e interdisciplinares, aproximando-se do campo de ação da promoção da saúde, consoante um dos compromissos da Carta de Ottawa (1986):

"reorientar os serviços de saúde e os recursos disponíveis para a promoção da saúde; incentivar a participação e colaboração de outros setores, outras disciplinas e, mais importante, da própria comunidade" (11).

Por isso, a abordagem da promoção da saúde é importante para o estudo dos direitos humanos das mulheres em dimensões, a partir da saúde como fundamental ao desenvolvimento das capacidades de vida. Para a Organização Mundial da Saúde (OMS), a promoção da saúde é um novo paradigma, porque considera as condições fundamentais para a saúde - paz, moradia, educação, alimentação, ecossistema estável, recursos sustentáveis, justiça social e equidade - para além das concepções e modelos biomédicos tradicionais (11).

A saúde, no conceito amplo dado pela OMS, é compreendida como

"um bem público de interesse nacional, caracterizado como o estado de pleno bem estar físico ou biológico, psíquico ou mental, social, cultural e ambiental da pessoa humana individual, coletiva e publicamente considerada" (12).

É um recurso para a vida - e melhoria de sua qualidade - e para o desenvolvimento humano, pois requer a abordagem da saúde como direito humano.

Em nível internacional, a consideração da saúde como direito humano fundamental é reafirmada em um importante pacto sobre a saúde dos povos, por meio de um dos primeiros documentos que originaram os debates sobre a promoção da saúde: a Declaração de Alma Ata, em 1978 (11).

O Brasil inspirou-se nesse pacto da Declaração de Alma Ata e no conceito de saúde da OMS, para elevá-la à condição de direito fundamental legalmente amparado. A Constituição Federal de 1988 (13) coloca a saúde como direito de todos e dever do Estado, pautada na concepção de justiça social, sob uma perspectiva integral e universal, que abrange ações de promoção, proteção e recuperação da saúde. Portanto, delineou a saúde pública sobre importantes princípios fundamentais de direitos humanos, especialmente os de distributividade, equidade, solidariedade e sustentabilidade (14). 
Este artigo estuda as ações dos PNPM, considerando a relação entre saúde e direitos humanos, sob a perspectiva da promoção da saúde. A motivação está na busca de conhecimentos sobre promoção da saúde das mulheres, sob a forma de compromisso do Estado com os direitos humanos. O objetivo é descrever as ações das três versões do Plano, segundo as dimensões de direitos humanos reconhecidos e garantidos, que contribuem para combater as discriminações e fomentar o desenvolvimento para mulheres em vulnerabilidade.

\section{A relação entre o direito à saúde e o Estado}

O direito e a saúde são importantes áreas de conhecimento e de práticas que possuem arcabouços próprios, mas também possuem muitas interligações entre si. A saúde e o direito estão historicamente imbricados como expressões das relações humanas (com o corpo, a natureza, a sociedade), e nas instâncias que dão suporte à vida. Confluem na história como tributários da humanidade (15).

Dessa inter-relação construída historicamente, aparecem os direitos humanos como fundamento do direito à saúde. Essa relação histórica beneficia o entendimento do direito à saúde como um dos direitos humanos e, por isso, indispensável para o respeito à dignidade da pessoa humana. $\mathrm{O}$ amplo conceito de saúde favorece de modo a interferir positivamente na interdisciplinaridade que tanto a área do direito quanto a da saúde exigem. Nesse entremeio está a atuação do Estado no processo de lutas e conquistas, permeando a política entre o direito e a saúde.

Schwartz (16) explica que a conexão entre direito e saúde acontece pela ideia de saúde. A evolução do conceito de saúde, que não tem mais o valor negativo da doença, incorpora componentes de outros sistemas do ambiente e não somente o acoplamento biomédico. O direito e a saúde são sistemas existentes dentro de um amplo ambiente, dependem desse ambiente e estabelecem relações entre si e com outros sistemas abertos. A saúde é o ponto de reflexão desse binômio, seu objetivo almejado e desejado, que garante seu constante processo evolutivo. Ela é percebida como um processo qualitativo que engloba os elementos que a circundam, tais como lazer, moradia e trabalho.

Portanto, a partir desse processo de abertura para incorporar outros elementos de seu entorno, pode-se entender que o direito à saúde não está ligado apenas aos aspectos de 
defesa da saúde como cura e prevenção de doenças. Em sua evolução, incorpora também outros elementos de bem-estar da vida humana e de sua proteção.

Por sua vez, essas novas incorporações de elementos à saúde exigem da atuação estatal um novo comportamento capaz de compreender a real dimensão das diversidades existentes, sem deixar de lado o cotidiano social e político.

\section{O Estado e o desenvolvimento humano}

Ao se falar sobre a concepção do papel do Estado Democrático de Direito na vida social, pode-se dizer que a sua atuação está presente em toda a sociedade, com o objetivo de proteger a universalidade dos direitos. É o que se pode depreender dos ensinamentos de Dallari (17), pois que a soberania e o poder do Estado têm "o objetivo de assegurar o respeito aos valores fundamentais da pessoa humana".

Continuamente, amplia-se a interferência dos poderes públicos na vida coletiva e individual, com o fim de prover e garantir tal proteção. Todavia, em um Estado Democrático de Direito, a extensão da atuação estatal é limitada por leis e princípios expressamente definidos ou não pelo ordenamento jurídico, também com o objetivo de proteger e garantir que direitos fundamentais não sejam violados.

O Estado Democrático é rearticulado para superar sua tendência expansiva, incompatível com a pluralidade sistêmica da sociedade atual. A partir das tensões e conflitos, estabelece uma relação construtiva, de modo a permitir que o direito não seja uma mera abstração e a política não seja um poder impotente por falta de referência legitimadora. (18).

Entretanto, entre a atuação estatal idealizada e a atuação real cotidiana presente em toda a sociedade, com o objetivo de proteger a universalidade dos direitos, há muitas interferências, imperfeições e lacunas, especialmente quando se analisam as problemáticas do Estado diante das profundas transformações pelas quais passa o mundo contemporâneo.

Sousa Santos (19) observa que o modelo de contrato social da modernidade, proveniente do consenso neoliberal, se baseia em critérios inclusivos, mas na verdade operam para reforçar a exclusão dos que não são exprimíveis na sociedade civil. O autor propõe um novo contrato social baseado em "sociabilidades alternativas", como resposta para solucionar os inconvenientes da exclusão provenientes do pré e pós-contratualismo sobre os países periféricos. Para tanto, é preciso pensar e investir na "redescoberta 
democrática do trabalho" e na "transformação do Estado em um novo movimento social". O Estado passa a ser um articulador e coordenador, e não mais um centralizador, para lutar por uma democracia redistributiva, não limitada à democracia representativa e sim combinada à participativa, transformando o Estado em componente do espaço público não estatal (19).

Sen (20) também critica a atuação estatal na atualidade, e propõe alternativas contra a degradação humana e social advindas da forte interferência da economia na política. Propugna por um fortalecimento da democracia e da liberdade. Estes dois pilares devem ser trabalhados como fundamentos do desenvolvimento, que deve ser um processo de expansão das liberdades substanciais das pessoas. O desenvolvimento não deve ser visto de forma restrita como fim e focado em fatores econômicos. Eles são importantes, mas devem ser considerados como meios de desenvolvimento das liberdades, em conjunto com outros fatores como as políticas sociais nas áreas de educação e saúde, e a garantia dos direitos civis.

Conforme explica Sen (20), são exemplos de liberdades substantivas: ter condições de evitar a fome, saber ler, ter participação política, dentre outras. Ao analisar as realidades econômicas e sociais de alguns países, apurou ser necessário que os países subdesenvolvidos promovam políticas sociais (liberdades), porque estas os ajudarão a alcançar o desenvolvimento.

Sob a perspectiva do direito, também há a ideia de que o desenvolvimento deve ser baseado no ser humano, porque a vulnerabilidade econômico-social leva à vulnerabilidade dos direitos civis e políticos, o que acarreta a fragilização da democracia. A necessidade de se pensar em formas de desenvolvimento que se preocupem com políticas sociais é fundamental para apontar as funções que o Estado deve assumir para assegurar um desenvolvimento sustentável e democrático, pautado por uma agenda de inclusão nos planos local, regional e global (21).

O que esses estudiosos sustentam é a necessária de contínua luta por direitos e sua defesa, tendo em vista que a existência de injustiças, desigualdades e exclusões gera o conflito como oportunidade de a sociedade exigir, e fazer uma existência mais igualitária para todas as pessoas. 
O Estado Democrático de Direito tem como centralidade os direitos fundamentais e sua efetivação, sob a forma de compromisso com os direitos transindividuais, a igualdade, a inclusão e a liberdade.

\section{A saúde como direito}

Os direitos humanos constituem o fundamento do Estado Democrático, possuem validade universal para todos os povos e tempos, independentemente de sua vinculação com certa ordem constitucional, por isso são considerados como supranacionais (22).

A II Conferência Mundial sobre Direitos Humanos (Viena, 1993), reconheceu a legitimidade da preocupação internacional com os direitos humanos; e que o direito ao desenvolvimento é um direito humano fundamental, e a saúde é abordada como um de seus pilares (3).

Os direitos fundamentais possuem uma destacada característica, a de vinculação dos poderes públicos, que os coloca como obrigações indeclináveis do Estado. Faz com que a garantia e a realização dos direitos fundamentais sejam dever do Estado, que não pode ser afastado sob pena de ofensa à Constituição. Essa característica representa a limitação imposta pela soberania popular aos poderes constituídos do Estado, para racionalizar a atuação e organização destes, de forma a proteger e garantir as liberdades e direitos dos indivíduos (23).

Acentua-se que os direitos sociais exigem que o Estado aja prestando serviços ou atividades, para melhorar as condições de vida e o desenvolvimento da população, tentando atenuar desigualdades e moldar o país para um futuro melhor. O que se quer é um Estado ativo, interventor, implementador e transformador (24).

É sob essa ótica que as políticas públicas na área de saúde possuem importante papel, porque "implica uma abordagem mais complexa impondo a reformulação de conceitos e práticas, tanto na área da saúde quanto do Estado e o seu papel frente à sociedade. " (25).

A partir disso, pode-se dizer que a saúde como direito é: direito humano, fundamental e social. Porque a saúde é condição elementar à dignidade, liberdade e igualdade humana; seu direito trata de situações jurídicas sem as quais a pessoa humana não se realiza, não convive e, às vezes, nem mesmo sobrevive; e, porque possibilita melhores condições de 
vida aos mais fracos, para realizar a igualização de situações sociais desiguais. Portanto, o direito à saúde é reconhecido como direito universal e igualitário.

Por conseguinte, o enfoque dos direitos humanos é um aporte de cuidado e esperança, para se estudar a saúde como direito humano (26).

\section{As dimensões dos direitos fundamentais}

Segundo Bobbio (27) os direitos fundamentais tornam-se um dos principais indicadores do progresso histórico da sociedade, caracterizado por lutas em defesa de novas liberdades contra velhos poderes, e nascidos de modo gradual, não todos de uma vez e nem de uma vez por todas. Por serem graduais, classificou os direitos fundamentais em "gerações de direitos", assim apresentadas:

a) os direitos de primeira geração são as liberdades;

b) os direitos de segunda geração são os direitos sociais;

c) os direitos de terceira geração são heterogêneos e vagos, sendo o mais importante deles "o direito de viver num ambiente não poluído";

d) os direitos de quarta geração são os que se referem aos efeitos traumáticos das pesquisas biológicas e genéticas.

Outros estudiosos defendem o uso do termo "dimensão" ao invés de "geração", porque "esses direitos não são substituídos ou alterados de tempos em tempos, mas resultam num processo de fazer-se e de complementaridade permanente. " O termo "geração" poderia induzir a uma ideia de sucessão cronológica de direitos normatizados, como se os posteriores derrogassem os das gerações anteriores (28) (29).

Nessa concepção, apresentam as descrições de direitos como dimensões, e acrescentam mais uma dimensão, assim consideradas:

a) os direitos de primeira dimensão são os de: igualdade, liberdade, propriedade, manifestação de pensamento, vida e de segurança dos indivíduos;

b) os direitos de segunda dimensão são os direitos sociais, econômicos e culturais. Baseiam-se na noção de igualdade material (redução de desigualdades), no pressuposto de que não adianta ter liberdades sem condições mínimas para exercê-las, como: saúde, educação, moradia, segurança pública, alimentação, trabalho, previdência social, lazer etc.; 
c) os direitos de terceira dimensão são transindividuais, difusos e coletivos. São os direitos de solidariedade, paz, autodeterminação dos povos, desenvolvimento, meio ambiente, qualidade de vida, comunicação, informação e direitos do consumidor;

d) os direitos de quarta dimensão são os direitos de democracia, informação e pluralismo. Todavia, Bobbio (27) coloca que são os direitos relacionados às pesquisas biológicas, bioética, biotecnologia e de engenharia genética. Por exemplo: gestação, aborto, eutanásia, clonagens, transplantes etc.;

e) os direitos de quinta dimensão são os direitos decorrentes da aplicação da cibernética no mundo virtual, do desenvolvimento de tecnologias aplicadas ao espaço cibernético, capazes de romper limites territoriais e estabelecer conflitos entre países (28) (29).

A consideração sobre o surgimento dos direitos e suas dimensões é importante para verificar os direitos conquistados pelas mulheres, posicionados sob a perspectiva de avanços em direitos à saúde como direito ao desenvolvimento humano, segundo as dimensões de direitos humanos fundamentais.

\section{Metodologia}

Efetuou-se um enfoque qualitativo, com objetivo de uma pesquisa exploratória. Quanto aos meios empregados, utilizou-se a pesquisa bibliográfica por revisão narrativa simples, e a documental como procedimento técnico de observação indireta através de documentos oficiais, tendo como fontes dos dados secundários os textos dos três PNPM (I PNPM, II PNPM e III PNPM, disponíveis em: <http://www.spm.gov.br>).

Utilizaram-se apenas dados de domínio público e acesso irrestrito, constantes em sítios de organizações e agências, governamentais e não governamentais (nacionais e internacionais), na World Wide Web.

Para categorizar as ações das três versões do Plano, segundo as dimensões de direitos humanos fundamentais, seguiu-se a classificação de dimensões dos direitos (28) (29).

\section{Resultados}

Em termos de direitos, em suas três versões o Plano apresenta novas propostas e abordagens de direitos de primeira, segunda e terceira dimensão, conforme se observa nos Quadros 1 e 2. 
Quadro 1. Categorização das ações dos Planos Nacionais de Políticas para Mulheres segundo a dimensão de direitos

\begin{tabular}{|c|c|c|c|}
\hline \multirow{2}{*}{$\begin{array}{c}\text { Ações quanto à } \\
\text { área estratégica } \\
\text { de atuação }\end{array}$} & \multicolumn{3}{|c|}{ Direitos } \\
\hline & $1^{\text {a }}$ dimensão & 2ª dimensão & 3ª dimensão \\
\hline \multirow{3}{*}{ Trabalho } & $\begin{array}{l}\text { I PNPM: liberdade; } \\
\text { igualdade; segurança } \\
\text { e propriedade. }\end{array}$ & $\begin{array}{l}\text { I PNPM: saúde; trabalho; } \\
\text { segurança pública; } \\
\text { previdência e moradia. }\end{array}$ & $\begin{array}{l}\text { I PNPM: meio ambiente; } \\
\text { qualidade de vida; } \\
\text { desenvolvimento e direito } \\
\text { das deficientes. }\end{array}$ \\
\hline & $\begin{array}{l}\text { II PNPM: apenas } \\
\text { mantém as ações do I } \\
\text { PNPM. }\end{array}$ & $\begin{array}{l}\text { II PNPM: mantém as ações } \\
\text { do I PNPM e acrescenta } \\
\text { proteção social. }\end{array}$ & $\begin{array}{l}\text { II PNPM: apenas mantém } \\
\text { as ações do I PNPM. }\end{array}$ \\
\hline & $\begin{array}{l}\text { III PNPM: apenas } \\
\text { mantém as ações do II } \\
\text { PNPM. }\end{array}$ & $\begin{array}{l}\text { III PNPM mantém as ações } \\
\text { do IIPNPM e acrescenta: } \\
\text { educação e alimentação. }\end{array}$ & $\begin{array}{l}\text { III PNPM apenas mantém } \\
\text { as ações do II PNPM. }\end{array}$ \\
\hline \multirow{3}{*}{ Educação } & $\begin{array}{l}\text { I PNPM: liberdade; } \\
\text { igualdade e } \\
\text { manifestação de } \\
\text { pensamento. }\end{array}$ & $\begin{array}{l}\text { I PNPM: saúde; educação e } \\
\text { segurança pública. }\end{array}$ & $\begin{array}{l}\text { I PNPM: desenvolvimento; } \\
\text { comunicação; direito à } \\
\text { informação; humanismo, } \\
\text { sororidade e } \\
\text { solidariedade; democracia } \\
\text { e pluralismo. }\end{array}$ \\
\hline & $\begin{array}{l}\text { II PNPM: mantém as } \\
\text { ações do I PNPM e } \\
\text { acrescenta direitos } \\
\text { sexuais e reprodutivos; } \\
\text { e liberdade de } \\
\text { locomoção. }\end{array}$ & $\begin{array}{l}\text { II PNPM: apenas mantém } \\
\text { as ações do IPNPM. }\end{array}$ & $\begin{array}{l}\text { II PNPM: apenas mantém } \\
\text { as ações do I PNPM. }\end{array}$ \\
\hline & $\begin{array}{l}\text { III PNPM: apenas } \\
\text { mantém as ações do II } \\
\text { PNPM. }\end{array}$ & $\begin{array}{l}\text { III PNPM: apenas mantém } \\
\text { as ações do II PNPM. }\end{array}$ & $\begin{array}{l}\text { III PNPM: apenas mantém } \\
\text { as ações do II PNPM. }\end{array}$ \\
\hline \multirow{3}{*}{$\begin{array}{l}\text { Saúde, direitos } \\
\text { sexuais e direitos } \\
\text { reprodutivos }\end{array}$} & $\begin{array}{l}\text { I PNPM: liberdade; } \\
\text { igualdade; direitos } \\
\text { sexuais e reprodutivos. }\end{array}$ & $\begin{array}{l}\text { I PNPM: saúde; educação e } \\
\text { trabalho. }\end{array}$ & $\begin{array}{l}\text { I PNPM: humanismo, } \\
\text { sororidade e } \\
\text { solidariedade; democracia } \\
\text { e pluralismo; qualidade de } \\
\text { vida; desenvolvimento e } \\
\text { direito à informação. }\end{array}$ \\
\hline & $\begin{array}{l}\text { II PNPM: apenas } \\
\text { mantém as ações do I } \\
\text { PNPM. }\end{array}$ & $\begin{array}{l}\text { II PNPM: apenas mantém } \\
\text { as ações do I PNPM. }\end{array}$ & $\begin{array}{l}\text { II PNPM: apenas mantém } \\
\text { as ações do I PNPM. }\end{array}$ \\
\hline & $\begin{array}{l}\text { III PNPM: apenas } \\
\text { mantém as ações do II } \\
\text { PNPM. }\end{array}$ & $\begin{array}{l}\text { III PNPM: apenas mantém } \\
\text { as ações do II PNPM. }\end{array}$ & $\begin{array}{l}\text { III PNPM: apenas mantém } \\
\text { as ações do II PNPM. }\end{array}$ \\
\hline
\end{tabular}




\begin{tabular}{|l|l|l|l|}
\hline \multirow{2}{*}{$\begin{array}{c}\text { Ações quanto à } \\
\text { área estratégica } \\
\text { de atuação }\end{array}$} & \multicolumn{3}{|c|}{ Direitos } \\
\cline { 2 - 4 } & \multicolumn{1}{|c|}{$\mathbf{1}^{\text {a } \text { dimensão }}$} & \multicolumn{1}{|c|}{$\mathbf{2}^{\text {a dimensão }}$} & \multicolumn{1}{|c|}{$\mathbf{3}^{\text {a dimensão }}$} \\
\hline \multirow{4}{*}{$\begin{array}{l}\text { Enfrentamento à } \\
\text { violência }\end{array}$} & $\begin{array}{l}\text { I PNPM: liberdade. } \\
\text { II PNPM: apenas } \\
\text { mantém as ações do I } \\
\text { PNPM. }\end{array}$ & $\begin{array}{l}\text { I PNPM: saúde; segurança; } \\
\text { trabalho e educação. } \\
\text { as ações do I PNPM. }\end{array}$ & $\begin{array}{l}\text { I PNPM: qualidade de } \\
\text { vida; comunicação e } \\
\text { direito à informação. }\end{array}$ \\
\cline { 2 - 4 } & $\begin{array}{l}\text { III PNPM: apenas } \\
\text { mantém as ações do II } \\
\text { PNPM. }\end{array}$ & $\begin{array}{l}\text { III PNPM: apenas mantém } \\
\text { as ações do II PNPM. }\end{array}$ & $\begin{array}{l}\text { III PNPM: apenas mantém } \\
\text { as ações do I PNPM. }\end{array}$ \\
\hline
\end{tabular}

Fonte: elaborado pelas autoras com dados da pesquisa documental.

Quadro 2. Categorização das ações incluídas apenas nos II e III Planos Nacionais de Políticas para Mulheres segundo a dimensão de direitos

\begin{tabular}{|c|c|c|c|}
\hline \multirow{2}{*}{$\begin{array}{l}\text { Ações quanto à } \\
\text { área estratégica } \\
\text { de atuação }\end{array}$} & \multicolumn{3}{|c|}{ Direitos } \\
\hline & 1ª dimensão & $2^{\text {a }}$ dimensão & $3^{\text {a }}$ dimensão \\
\hline \multirow{2}{*}{$\begin{array}{l}\text { Espaços de poder } \\
\text { e decisão }\end{array}$} & $\begin{array}{l}\text { II PNPM: liberdade; } \\
\text { igualdade; } \\
\text { manifestação de } \\
\text { pensamento e direitos } \\
\text { políticos. }\end{array}$ & \multirow[t]{2}{*}{ Não houve. } & \multirow[t]{2}{*}{ Não houve. } \\
\hline & $\begin{array}{l}\text { III PNPM: apenas } \\
\text { mantém as ações do } \\
\text { II PNPM. }\end{array}$ & & \\
\hline \multirow{2}{*}{$\begin{array}{l}\text { Desenvolvimento } \\
\text { sustentável }^{1}\end{array}$} & $\begin{array}{l}\text { II PNPM: liberdade e } \\
\text { igualdade. }\end{array}$ & $\begin{array}{l}\text { II PNPM: saúde; } \\
\text { educação; moradia; } \\
\text { alimentação e trabalho. }\end{array}$ & $\begin{array}{l}\text { II PNPM: desenvolvimento; } \\
\text { democracia e pluralismo; } \\
\text { meio ambiente e qualidade } \\
\text { de vida. }\end{array}$ \\
\hline & $\begin{array}{l}\text { III PNPM apenas } \\
\text { mantém as ações do } \\
\text { II PNPM. }\end{array}$ & $\begin{array}{l}\text { III PNPM apenas mantém } \\
\text { as ações do II PNPM. }\end{array}$ & $\begin{array}{l}\text { III PNPM apenas mantém as } \\
\text { ações do II PNPM. }\end{array}$ \\
\hline \multirow{2}{*}{$\begin{array}{l}\text { Direito à terra, } \\
\text { moradia digna e } \\
\text { infraestrutura social } \\
\text { nos meios rural e } \\
\text { urbano }^{1}\end{array}$} & $\begin{array}{l}\text { II PNPM: liberdade; } \\
\text { igualdade; segurança } \\
\text { e propriedade. }\end{array}$ & $\begin{array}{l}\text { II PNPM: saúde; moradia e } \\
\text { trabalho. }\end{array}$ & $\begin{array}{l}\text { II PNPM: meio ambiente; } \\
\text { qualidade de vida e } \\
\text { desenvolvimento. }\end{array}$ \\
\hline & $\begin{array}{l}\text { III PNPM: apenas } \\
\text { mantém as ações do } \\
\text { II PNPM. }\end{array}$ & $\begin{array}{l}\text { III PNPM: apenas mantém } \\
\text { as ações do II PNPM. }\end{array}$ & $\begin{array}{l}\text { III PNPM: apenas mantém } \\
\text { as ações do II PNPM. }\end{array}$ \\
\hline
\end{tabular}




\begin{tabular}{|c|c|c|c|}
\hline \multirow{2}{*}{$\begin{array}{l}\text { Ações quanto à } \\
\text { área estratégica } \\
\text { de atuação }\end{array}$} & \multicolumn{3}{|c|}{ Direitos } \\
\hline & 1à dimensão & 2a dimensão & 3a dimensão \\
\hline \multirow[t]{2}{*}{$\begin{array}{l}\text { Cultura, } \\
\text { comunicação, } \\
\text { mídia e esporte }^{1}\end{array}$} & $\begin{array}{l}\text { II PNPM: liberdade; } \\
\text { igualdade e } \\
\text { manifestação de } \\
\text { pensamento. }\end{array}$ & $\begin{array}{l}\text { II PNPM: saúde; } \\
\text { educação; segurança } \\
\text { pública; trabalho e cultura. }\end{array}$ & $\begin{array}{l}\text { II PNPM: humanismo, } \\
\text { sororidade e solidariedade; } \\
\text { democracia e pluralismo; } \\
\text { qualidade de vida; } \\
\text { desenvolvimento e } \\
\text { comunicação. }\end{array}$ \\
\hline & $\begin{array}{l}\text { III PNPM: apenas } \\
\text { mantém as ações do } \\
\text { IIPNPM. }\end{array}$ & $\begin{array}{l}\text { III PNPM: apenas mantém } \\
\text { as ações do IIPNPM. }\end{array}$ & $\begin{array}{l}\text { III PNPM: apenas mantém } \\
\text { as ações do IIPNPM. }\end{array}$ \\
\hline \multirow[t]{2}{*}{$\begin{array}{l}\text { Enfrentamento do } \\
\text { racismo, sexismo e } \\
\text { lesbofobia }^{1,2}\end{array}$} & $\begin{array}{l}\text { II PNPM: liberdade e } \\
\text { igualdade. }\end{array}$ & $\begin{array}{l}\text { II PNPM: saúde; } \\
\text { educação; segurança } \\
\text { pública; trabalho e cultura. }\end{array}$ & $\begin{array}{l}\text { II PNPM: humanismo, } \\
\text { sororidade e solidariedade; } \\
\text { democracia e pluralismo; } \\
\text { qualidade de vida; } \\
\text { desenvolvimento e } \\
\text { comunicação. }\end{array}$ \\
\hline & $\begin{array}{l}\text { III PNPM: apenas } \\
\text { mantém as ações do } \\
\text { II PNPM. }\end{array}$ & $\begin{array}{l}\text { III PNPM: apenas mantém } \\
\text { as ações do II PNPM. }\end{array}$ & $\begin{array}{l}\text { III PNPM: apenas mantém } \\
\text { as ações do II PNPM. }\end{array}$ \\
\hline \multirow{2}{*}{$\begin{array}{l}\text { Enfrentamento das } \\
\text { desigualdades } \\
\text { geracionais }{ }^{1,3}\end{array}$} & $\begin{array}{l}\text { II PNPM: liberdade e } \\
\text { igualdade. }\end{array}$ & $\begin{array}{l}\text { II PNPM: saúde; } \\
\text { educação; trabalho; cultura } \\
\text { e segurança pública. }\end{array}$ & $\begin{array}{l}\text { II PNPM: humanismo, } \\
\text { sororidade e solidariedade; } \\
\text { democracia e pluralismo; e } \\
\text { direitos da idosa, da infância } \\
\text { e da juventude. }\end{array}$ \\
\hline & $\begin{array}{l}\text { III PNPM: apenas } \\
\text { mantém as ações do } \\
\text { II PNPM. }\end{array}$ & $\begin{array}{l}\text { III PNPM: apenas mantém } \\
\text { as ações do II PNPM. }\end{array}$ & $\begin{array}{l}\text { III PNPM: apenas mantém } \\
\text { as ações do II PNPM. }\end{array}$ \\
\hline
\end{tabular}

Fonte: elaborado pela autora com dados da pesquisa documental.

${ }^{1}$ Estratégias e ações consideradas pela SPM a partir do II PNPM.

2,3 O Plano não apresentou detalhamentos em separado para as ações dessas estratégias. Considerou que se encontram distribuídas nas demais estratégias. A apuração aqui apresentada foi uma garimpagem nas ações das outras estratégias.

A maior parte dos direitos aparecem no I PNPM, quando foram definidas quatro estratégias: trabalho, educação, saúde e violência. Nos demais Planos, outros direitos são acrescentados, mas a maioria desses acréscimos foram em decorrência das seis novas estratégias e suas ações: espaços de poder, meio ambiente, terra e moradia, cultura e comunicação, combate às discriminações e às desigualdades. Contudo, em todas essas novas estratégias, o alcance dos direitos também vai até a terceira dimensão. 
As dimensões de direitos contidas nos Planos, em geral, são ricas em termos de ações que defendem. Poucas são estratégias que contemplam apenas uma ou duas ações. Os direitos de primeira dimensão estão presentes em todas as estratégias. A estratégia que apresenta ações com menor alcance em dimensão de direitos é a dos espaços de poder, porque suas ações são muito específicas, sem inter-relação com a saúde ou estratégias de ação que possibilitem (de forma direta) alcançar outras dimensões de direito.

Devido às lacunas e limitações presentes nos temas e propostas de ações, não há alcance aos direitos de quarta e quinta dimensões. Faltam propostas de inserção de temas relacionados às mulheres quanto aos aspectos em bioética, biotecnologia, cibernética $e$ tecnologias da informação, embora as mulheres tenham sido pioneiras no avanço legislativo do marco referencial da internet no Brasil, com a aprovação da Lei n. 12.737/2012 (Lei Carolina Dieckman).

Além do direito à saúde, as ações propostas inserem-se mais nos direitos sociais relacionados à educação, trabalho, moradia e segurança pública. Poucas ações contemplam os direitos sociais relacionados à alimentação, lazer e previdência social. Pode-se considerar que há avanços em áreas estratégicas para as reivindicações das mulheres, mas pelo conteúdo que as ações de todos os Planos englobam, ainda é preponderante a visão da saúde da mulher como saúde materna (pré-natal, parto e puerpério).

Quanto aos aspectos relacionados ao desenvolvimento humano, de modo geral, pelos resultados apresentados nos quadros acima, apesar das limitações apontadas, as estratégias e ações podem contribuir para desenvolver cidadania, novos pensamentos e direitos que visem o incremento da vivência social; a equidade; o aumento do conhecimento e ações de promoção da saúde para diminuir as vulnerabilidades; e melhoria da qualidade de vida das mulheres. Isso pode se dar tanto de forma direta quanto indireta, pois as estratégias e as ações estão planejadas com elementos que visam aspectos como: a) o combate às desigualdades, à discriminação e à violência, sob todas as formas e em todos os ambientes; b) considerar as mulheres como sujeitos de direitos e sujeitos políticos, com direito ao desenvolvimento econômico e social promovido de maneira sustentável, com respeito ao meio-ambiente e por meio do uso adequado dos recursos naturais; e, c) considerar a implementação de políticas mais amplas, com incidência sobre a vida das mulheres e sobre a dinâmica das relações de gênero, para assegurar-Ihes mais autonomia e justiça social. 
As ações propostas possuem uma perspectiva emancipatória da mulher, ao considerala como sujeito político de direitos e representam um ganho importante para os aspectos inclusivos e emancipatórios que os direitos humanos significam para as mulheres.

Observa-se que, em todos os PNPM, a atenção às propostas inovadoras e com base nas perspectivas dos direitos humanos são mantidas, como forma de demonstrar que os Planos têm avançado no sentido de contrapor-se à exclusão de segmentos de mulheres; à discriminação; e às práticas natalistas de controle do corpo e da sexualidade, para incorporar a visão dos direitos humanos da mulher, sob um novo conceito da mulher como sujeito ativo no cuidado de sua saúde em todos os ciclos de vida (10).

Todavia, embora os textos dos PNPM tragam essa narrativa da busca de inovações e avanços, as ações propostas concentram-se mais nas práticas tradicionais para a saúde reprodutiva da mulher nos períodos pré-natal, gravídico obstétrico e puerperal.

Os Planos também apresentam lacunas em várias estratégias: pesquisas biológicas e em outras ciências; avanços na legislação sobre o aborto (legalização ou descriminalização), inclusão em tecnologias cibernéticas.

Ainda sobre os aspectos de continuidade dos avanços e novas propostas, cada Plano retoma os pontos e propostas que não foram aprovados em seus antecessores. Reconhecem que, como política de promoção da igualdade e de valorização das diversidades, o PNPM encontra-se em permanente processo de construção e aperfeiçoamento, e constitui-se como responsabilidade de todos os órgãos governamentais.

\section{Discussão}

Considerando-se pela ótica das dimensões dos direitos, ao dar importância e visibilidade para grupos de mulheres, como indígenas, da terra, do campo e da floresta, os PNPM trazem implicitamente à tona as conquistas das mulheres por uma Carta Magna como Constituição Cidadã, pautada na igualdade e no pluralismo. Ao que Lenza (30) sinaliza como o Novo Constitucionalismo Democrático Latino Americano, de um Estado pluralista e multicultural. Trazem como resgate, a marca de um Brasil que se abre para os novos direitos da natureza, da memória e da história através das mulheres.

Além disso, há o reconhecimento da maior vulnerabilidade social e econômica, especialmente para alguns grupos de mulheres. Conforme explicam Campos (31) e França 
e Lima (32), as condições e os modos de produção de bens e seu consumo, o agronegócio, o desenvolvimento econômico e social, e a degradação ambiental têm um impacto perverso sobre a vida, a saúde e a qualidade de vida das mulheres do campo e da floresta. São mulheres destituídas de proteção social, desprovidas de meios de subsistência, dependentes da monocultura, do extrativismo ou da coletoria nativa, e vivendo de modo mais intenso a feminização da pobreza.

Embora o II e III PNPM tragam mais ações com a finalidade de alcançar a saúde integral para as mulheres e dar atenção às transversalidades entre eixos estratégicos importantes, a fragilidade dessas ações para garantir a integralidade ainda se repercute.

A saúde sexual e a saúde reprodutiva das mulheres, como direitos sexuais e direitos reprodutivos, na perspectiva dos direitos humanos, constituem-se em importante conquista dos movimentos feministas pela igualdade de gênero, inicialmente corporificada no PAISM e depois ampliada com a PNAISM. Para além da condição de gênero, a PNAISM representa um grande avanço no sentido da promoção da saúde da mulher, pelos novos conceitos que incorpora à atenção à saúde, tendo as mulheres como sujeitos ativos no cuidado de sua saúde. Como conceitos integrantes da saúde integral da mulher, o direito sexual é o exercício da vivência da sexualidade sem constrangimento; e o direito reprodutivo é o exercício da maternidade voluntária e da contracepção auto decidida $(7,33)$. As mulheres são vistas como sujeitos com autonomia para decidir sobre seus corpos e demais aspectos de suas vidas, e no dizer da promoção da saúde, representa um empoderamento.

Sob a perspectiva enunciada nos PNPM, o direito à saúde das mulheres - saúde integral das mulheres, direitos sexuais e direitos reprodutivos - deveria ser implementado como um desenvolvimento do conceito de saúde como uma noção de construção de direitos de cidadania. Desse modo, a saúde integral não seria apenas acesso universal e gratuito a contraceptivos, pré-natal, consultas, exames laboratoriais e assistência ao parto. As mulheres não mais seriam tratadas dentro do espaço privado restrito ao doméstico, passariam para o âmbito mais amplo do espaço político. A incorporação dos direitos sexuais, direitos reprodutivos e direito ao planejamento familiar deveria ter papel fundamental para dar às mulheres autonomia cidadã para decidirem sobre os seus corpos e suas próprias vidas. Conforme descreve a Declaração de Pequim (1995), essas mudanças representam a incorporação de outros direitos, por meio de ações mais complexas, com interação em 
termos de moradia, creche, educação, trabalho, divisão do trabalho doméstico e dos cuidados com familiares, respeito às diversidades etc. (5).

Há áreas estratégicas de grande importância para a promoção da saúde, com poucas ou nenhuma ação orientada para as especificidades em relação às mulheres por grupos vulneráveis. Há também poucas ações que estabeleçam um diálogo entre a área da saúde com outras áreas e que busquem oferecer condições de empoderamento, combate à discriminação e inserção no mercado de trabalho.

O direito à saúde é universal, mas por causa das vulnerabilidades a que estão submetidas, esse direito deve ser dado às mulheres com adequações/vantagens específicas pelo poder executivo. É importante dar destaque a essa questão, porque há grupos de mulheres que, além de suas necessidades específicas, estão mais vulneráveis programaticamente. É o caso das indígenas, que estão sob condição legislativa especial e atenção da Fundação Nacional do Índio (FUNAI) para assistência, o que dificulta alcançálas sem empenho transversal e intersetorial (34).

O Estado elaborou inúmeras leis para proteger a mulher no período gestacional e puerperal. Todavia, falta atenção para áreas importantes como a saúde ocupacional; a saúde mental não atrelada à gestação; e ações relacionadas à alimentação saudável, atividades físicas e atenção geriátrica.

Sob a perspectiva dos direitos humanos, pode-se dizer que a saúde integral para as mulheres desempenha relevante papel para a afirmação, conquista, respeito e cumprimento de todas as prerrogativas e oportunidades para a concretização das suas capacidades de desenvolvimento humano. $\mathrm{O}$ direito à saúde faz a interação entre todos os direitos sociais, que possuem como fundamento a defesa da dignidade humana (35).

Apesar de poucos ou insuficientes, os avanços indicam que o Estado se propõe a estar mais atento às considerações e propostas apresentadas pelos movimentos feministas e de mulheres, tais como a elaboração de leis para proteção à mulher contra as violências e abusos e a participação das mulheres nos espaços de poder público, com metas de inclusão obrigatória em partidos. Entretanto, expressam também as dificuldades para implementação de ações de estratégias potentes e centrais, pelo fato de haver dificuldades de articulação entre os movimentos e representações de mulheres com o Estado. Há também dificuldades relacionadas ao comportamento e rejeição às mudanças culturais da sociedade, ainda 
influenciada por considerações sociopolíticas do patriarcado, por vários tipos de discriminações e por ponderações religiosas. Afinal, "os avanços do ponto de vista dos direitos e da redução das desigualdades são, historicamente, conquistas, nunca presentes ou dádivas." (32).

Isso é importante, pois os direitos precisam de contínua pressão dos movimentos feministas e de mulheres para serem alcançados em futuras legislações, por meio de estratégias de enfrentamento aos impedimentos culturais e políticos (36) (32).

Em relação ao Estado, as dificuldades emergem porque as ações exigem um novo paradigma de planejamento e gestão de políticas públicas, pautado na intersetorialidade e na transversalidade. Isso demanda apoio de setores e órgãos estatais direta e indiretamente ligados à SPM e atuação junto aos governos estaduais e municipais para implementar as ações do PNPM. São limitações políticas e de estruturas sociais.

Depreende-se que os direitos humanos das mulheres consistem no dever que as políticas públicas têm de atingir e modificar a vida em direção ao desenvolvimento humano, estabelecendo relações mais igualitárias. É necessário ir além da desigualdade de gênero, para que nenhum grupo de mulheres esteja esquecido em suas necessidades e especificidades, por causa de políticas públicas que as homogeneízam com base em critérios de dominação que perpetuam injustiças.

As ações propostas buscam potencializar a luta das mulheres contra as nocivas influências das dominações históricas e sociais que as alijou de importantes processos dos âmbitos políticos, sociais e econômicos. Trazem as atualizações e os significados das lutas das mulheres, respeitando os conhecimentos e os saberes presentes em suas diversidades: sejam elas tradicionais, indígenas, camponesas, urbanas, rurais etc.

Da explicação de Sousa Santos (37), as políticas recorrem à linguagem dos direitos humanos para reinventar a linguagem da emancipação. Contudo, para poder operar de forma contra hegemônica, os direitos humanos têm de ser reconceitualizados como multiculturais. Uma política emancipatória deve saber distinguir entre a luta pela igualdade e a luta pelo reconhecimento igualitário das diferenças, a fim de poder travar ambas as lutas eficazmente.

Como dimensões de direitos, as conquistas das mulheres repercutem no tempo e no espaço de forma dinâmica, acontecem concomitantemente. Não são dados como 
sobrepostos ou superados em relação aos novos patamares de propostas. Estruturam-se em conjunto como direitos à igualdade e à diferença, pela e para a autonomia das mulheres.

\section{Considerações finais}

Por meio das propostas de ações dos PNPM o Brasil demonstra que busca seguir as recomendações da CEDAW e dos demais tratados e convenções de direitos humanos e das mulheres celebrados internacionalmente através da ONU. Esse fato representa um avanço no respeito aos direitos humanos e aos direitos das mulheres, visto que é um país onde a democracia e a Constituição têm apenas 30 anos de implantação; e tem marcas históricas e sociais profundas deixadas por regimes de governos colonizadores, escravistas, machistas, sexistas e totalitários, que ainda incidem sobre todas as estruturas. No campo do direito à saúde, também foram observados avanços, mas que precisam de um olhar mais adequado, tendo em vista as condições de vulnerabilidade, a intersetorialidade e transversalidade a que estão sujeitos.

Decerto é um avanço que demonstra fragilidades e insuficiências, mas é uma melhoria. Para esse avanço, foi essencial a participação dos movimentos feministas e de mulheres em todos os momentos históricos do país. São conquistas conseguidas pelas mulheres, por certo com muitas lutas, esforços e humilhações. Como as mulheres exercem grandes influências e impulsionamentos sociais, suas conquistas refletem-se sobre toda a sociedade, no seu desenvolvimento e ampliação e respeito aos direitos humanos de todas as pessoas.

\section{Referências}

1. Organização das Nações Unidas - ONU/CEDAW (1979). Convenção sobre a Eliminação de Todas as Formas de Discriminação contra a Mulher - Cedaw 1979. Disponível em: http://www.compromissoeatitude.org.br/wpcontent/uploads/2012/11/SPM2006_CEDAW_portugues.pdf. Acesso em: novembro de 2017.

2. Organização das Nações Unidas - ONU MULHERES (2013). Declaração e Programa de Ação de Viena (1993). Disponível em: http://www.onumulheres.org.br/wpcontent/uploads/2013/03/declaracao_viena.pdf. Acesso em: maio de 2018.

3. Organização das Nações Unidas - ONU MULHERES (2013c). Convenção Interamericana para Prevenir, Punir e Erradicar a Violência Contra a Mulher "Convenção de Belém do Pará" (1994). Disponível em: http://www.onumulheres.org.br/wpcontent/uploads/2013/03/convencaobelem1994.pdf. Acesso em: março de 2018. 
4. Organização das Nações Unidas (1986). Declaração sobre o Direito ao Desenvolvimento. Resolução n.ำ 41/128 da Assembleia Geral das Nações Unidas, de 4 de dezembro de 1986.

5. Programa das Nações Unidas para o Desenvolvimento (PNUD). Relatório de Desenvolvimento Humano (RDH-PNUD). La revolución hacia la igualdad en la condición de los sexos. 1995. Disponível em: http://hdr.undp.org/en/reports/global/hdr1995. Acesso em: 12/01/2017.

6. Organização das Nações Unidas - ONU MULHERES (2013). Declaração e Plataforma de Ação de Pequim (1995). Disponível em: http://www.onumulheres.org.br/wpcontent/uploads/2013/03/declaracao_beijing.pdf. Acesso em: maio de 2018.

7. Brasil. Ministério da Saúde. Secretaria de Atenção à Saúde. Departamento de Ações Programáticas Estratégicas. Política Nacional de Atenção Integral à Saúde da Mulher: princípios e diretrizes / Ministério da Saúde, Secretaria de Atenção à Saúde, Departamento de Ações Programáticas Estratégicas. - Brasília: Editora do Ministério da Saúde, 2009. Disponível em:

http://bvsms.saude.gov.br/bvs/publicacoes/politica_nac_atencao_mulher.pdf. Acesso em: 08/09/2017.

8. Brasil. Presidência da República. Secretaria de Políticas para as Mulheres. I Plano Nacional de Políticas para as Mulheres. Brasília: Secretaria de Políticas para as Mulheres, 2004. Disponível em: http://www.spm.gov.br/assuntos/pnpm/publicacoes/pnpm-2013-2015em-2ago13.pdf. Acesso em: 08/09/2017.

9. Brasil. Presidência da República. Secretaria de Políticas para as Mulheres. II Plano Nacional de Políticas para as Mulheres. Brasília: Secretaria de Políticas para as Mulheres, 2008. Disponível em: http://www.spm.gov.br/assuntos/pnpm/publicacoes/pnpm-2013-2015em-2ago13.pdf. Acesso em: 08/09/2017.

10. Brasil. Presidência da República. Secretaria de Políticas para as Mulheres. III Plano Nacional de Políticas para as Mulheres. Brasília: Secretaria de Políticas para as Mulheres, 2013. Disponível em: http://www.spm.gov.br/assuntos/pnpm/publicacoes/pnpm-2013-2015em-2ago13.pdf. Acesso em: 08/09/2017.

11. Brasil. Ministério da Saúde. Secretaria de Políticas de Saúde. Projeto Promoção da Saúde. As Cartas de Promoção da Saúde. Brasília: Ministério da Saúde, 2002. Disponível em: http://bvsms.saude.gov.br/bvs/publicacoes//cartas_promocao.pdf. Acesso em: 20/08/2017.

12. Organização Mundial da Saúde. Regulamento Sanitario Internacional (2005). In: World Health Assembly - WHA58.3. Genebra, 2005 (espanhol).

13. Brasil. [Constituição (1988)]. Constituição da República Federativa do Brasil [recurso eletrônico]. Brasília: Câmara dos Deputados, Edições Câmara, 2016. - (Série textos básicos; n. 113). Disponível em: http://www.camara.leg.br/editora. Acesso em: 15/08/2016. 
14. Brasil. Ministério da Saúde. Secretaria de Vigilância em Saúde. Secretaria de Atenção à Saúde. Política Nacional de Promoção da Saúde: PNPS: revisão da Portaria MS/GM no 687, de 30 de março de 2006/ Ministério da Saúde, Secretaria de Vigilância em Saúde, Secretaria de Atenção à Saúde. - Brasília: Ministério da Saúde, 2015. Disponível em: http://www.saude.gov.br/bvs. Acesso em: 25/09/2016.

15. Vasconcelos LCF, Oliviera MHB. Direito e saúde. Aproximações para a demarcação de um novo campo de conhecimento. In: . Direito e saúde: um campo em construção. Rio de Janeiro:

Ediouro, 2009. Disponível em:

http:/www.siga.foicruz.br/arqivos/ss/documentos/editais/1_Direitoshuma.pdf. Acesso em: 03/01/2017.

16. Schwartz GAD. A autopoiese do sistema sanitário. Revista De Direito Sanitário, 2003, 4(1): 50-59.

17. Dallari DA. Elementos de teoria geral do Estado. 26르 ed. São Paulo: Saraiva, 2007.

18. Neves M. Entre Têmis e Leviatã: uma relação difícil. São Paulo: Martins Fontes, 2006.

19. Santos BS. Os sentidos da democracia: políticas do dissenso e hegemonia global. Petrópolis: Vozes, 1999.

20. Sen AK. Desenvolvimento como liberdade. Tradução: Laura Teixeira Motta. São Paulo: Companhia das letras, 2001.

21. Piovesan F. Direitos humanos, democracia e integração regional: os desafios da globalização. Revista da Procuradoria Geral do Estado, Porto Alegre, 2001, 24(53): 19-39.

22. Sarlet IW. A Eficácia dos Direitos Fundamentais - Uma Teoria dos Direitos

Fundamentais na Perspectiva Constitucional. Porto Alegre/RS: Livraria do Advogado, 2015.

23. Branco PGG. Direitos fundamentais. In: Mendes GF, Branco PGG, Coelho

IM. Hermenêutica constitucional e direitos fundamentais. Brasília: Brasília Jurídica, 2002.

24. Carvalho MS. A saúde como direito social fundamental na Constituição de 1988. Revista de Direito Sanitário. 2003, 4(2).

25. Verdi M, Caponi S. Reflexões sobre a promoção da saúde numa perspectiva bioética. Texto Contexto Enferm. 2005, 1(14):82-8. Disponível em:

http://www.scielo.br/scielo.php?pid=S0104-

07072005000100011\&script=sci_abstract\&tIng=pt. Acesso em: 19/01/2017.

26. Puras D. Human rights and the practice of medicine. Public Health Reviews 38:9, 2017. Disponível em: https://publichealthreviews.biomedcentral.com/track/pdf/10.1186/s40985017-0054-7. Acesso em: 2018.

27. Bobbio N. A era dos direitos. Tradução: Carlos Nelson Coutinho. Nova edição. Rio de Janeiro: Elsevier, 2004. 
28. Wolkmer AC. Direitos Humanos: novas dimensões e fundamentações. Direito em Debate, ljuí, 2003.

29. Bonavides P. Curso de Direito Constitucional. São Paulo: Malheiros, 18ª ed. 2006.

30. Lenza P. Direito constitucional esquematizado. 19ª ed. São Paulo: Saraiva, 2015.

31. Campos CSS. A face feminina da pobreza em meio a riqueza do agronegócio: trabalho e pobreza das mulheres em territórios do agronegócio no Brasil: o caso de Cruz Alta/RS. Buenos Aires: CLACSO, 2011. Disponível em:

http://bvsde.org.ni/clacso/publicaciones/A\%20face\%20feminina\%20da\%20pobreza.pdf. Acesso em: 07/03/2018.

32. França LG, Lima PM. Direitos humanos e questões de gênero. In: Gonçalves CMC. Direitos humanos e diversidade. Curitiba: Juruá, 2013.

33. Brasil. Ministério da Saúde. Secretaria de Atenção à Saúde. Departamento de Ações Programáticas Estratégicas. Direitos sexuais, direitos reprodutivos e métodos anticoncepcionais / Ministério da Saúde, Secretaria de Atenção à Saúde, Departamento de Ações Programáticas Estratégicas. - Brasília: Ministério da Saúde, 2009. Disponível em: http://bvsms.saude.gov.br/bvs/publicacoes/direitos_sexuais_reprodutivos_metodos_an ticoncepcionais.pdf. Acesso em: 08/09/2017.

34. Brasil. Coletânea da legislação indigenista brasileira. - Brasília: CGDTI/FUNAI, 2008.

35. Santos RP. Direitos humanos da pessoa com deficiência. In: Gonçalves CMC. Direitos humanos e diversidade. Curitiba: Juruá, 2013.

36. Pinheiro MB, Ogando AC. Os impactos dos Planos Nacionais de Políticas para as Mulheres nas políticas públicas no Brasil. In: I Simpósio Nacional sobre Democracia e Desigualdades, 2012, Brasília. Anais do I Simpósio Nacional sobre Democracia e Desigualdades, 2012. Disponível em: http://www.enap.gov.br/web/pt-br/detalhecurso;jsessionid=4885787C3DBCA03BE15A729D. Acesso em:15/05/2017.

37. Santos BS. Poderá o direito ser emancipatório? Coimbra/Portugal: Revista Crítica de Ciências Sociais, 2003 mai, 65:3-76. Disponível em:

http://www.boaventuradesousasantos.pt/media/pdfs/podera_o_direito_ser_emancipatorio_ RCCS65.PDF. Acesso em: 14/08/2017.

Como citar esse artigo:

Souza MEA, Tavares MFL, Rocha RM. Dimensões dos direitos fundamentais no Plano Nacional de Políticas para Mulheres. Cadernos Ibero-Americanos de Direito Sanitário. 2019 abr./jun.; 8(2): 09-30. 